\title{
Mediterranean diet during pregnancy and childhood respiratory and atopic outcomes: birth cohort study
}

\author{
Annabelle Bédard ${ }^{1}$, Kate Northstone ${ }^{2}$, A. John Henderson ${ }^{2}$ and \\ Seif 0 . Shaheen ${ }^{1}$
}

Affiliations: ${ }^{1}$ Centre for Primary Care and Public Health, Barts and The London School of Medicine and Dentistry, Queen Mary University of London, London, UK. ${ }^{2}$ Population Health Sciences, Bristol Medical School, University of Bristol, Bristol, UK.

Correspondence: Seif 0 . Shaheen, Centre for Primary Care and Public Health, Blizard Institute, Barts and The London School of Medicine and Dentistry, 58 Turner Street, London E1 2AB, UK.

E-mail: s.shaheendaqmul.ac.uk

@ERSpublications

Adherence to a Mediterranean diet during pregnancy is not associated with a reduced risk of asthma or other allergic outcomes in the offspring, but may be associated with increased small airway function in childhood http://bit.ly/382yGcF

Cite this article as: Bédard A, Northstone $\mathrm{K}$, Henderson AJ, et al. Mediterranean diet during pregnancy and childhood respiratory and atopic outcomes: birth cohort study. Eur Respir J 2020; 55: 1901215 [https:// doi.org/10.1183/13993003.01215-2019].

ABSTRACT Evidence for associations between Mediterranean diet during pregnancy and childhood asthma, allergy and related outcomes is conflicting. Few cohorts have followed children to school age, and none have considered lung function.

In the Avon Longitudinal Study of Parents and Children, we analysed associations between maternal Mediterranean diet score during pregnancy (estimated by a food frequency questionnaire, using an $a$ priori defined score adapted to pregnant women; score ranging from 0 (low adherence) to 7 (high adherence)) and current doctor-diagnosed asthma, wheeze, eczema, hay fever, atopy and lung function in 8907 children at 7-9 years. Interaction between maternal Mediterranean diet and maternal smoking in pregnancy was investigated.

The maternal Mediterranean diet score was not associated with asthma or other allergic outcomes. Weak positive associations were found between maternal Mediterranean diet score and childhood maximal mid-expiratory flow (forced expiratory flow at $25-75 \%$ of forced vital capacity $\left(\mathrm{FEF}_{25-75 \%}\right)$ ) after controlling for confounders. Higher Mediterranean diet scores were associated with increased $\mathrm{FEF}_{25-75 \%}$ $\mathrm{z}$-scores adjusted for age, height and $\operatorname{sex}(\beta 0.06,95 \%$ CI $0.01-0.12 ; \mathrm{p}=0.03$, comparing a score of $4-7$ versus a score of $0-3$ ). Stratifying associations by maternal smoking during pregnancy showed that associations with $\mathrm{FEF}_{25-75 \%}$ were only seen in children of never-/passive-smoking mothers, but no evidence for a statistically significant interaction was found.

Results suggest adherence to a Mediterranean diet during pregnancy may be associated with increased small airway function in childhood, but we found no evidence for a reduced risk of asthma or other allergic outcomes.

This article has an editorial commentary https://doi.org/10.1183/13993003.02437-2019

This article has supplementary material available from erj.ersjournals.com

Received: 20 June 2019 | Accepted after revision: 29 Nov 2019

Copyright $\odot$ ERS 2020. This article is open access and distributed under the terms of the Creative Commons Attribution Licence 4.0. 


\section{Introduction}

A Mediterranean diet is typified by a high intake of vegetables, legumes, fruits and nuts, unrefined cereals, fish and olive oil, a low-to-moderate intake of dairy products and a low intake of meat and poultry and saturated fats [1]. In a Dutch birth cohort study, low adherence to a Mediterranean-like diet in pregnancy was associated with lower birthweight [2], and a recent randomised controlled trial conducted in pregnant women found that a Mediterranean diet intervention (with additional extra virgin olive oil and pistachio nuts) reduced the rate of small-for-gestational-age newborns, prematurity and gestational weight gain [3]. It also reduced gestational diabetes [3], which has been associated with an increased risk of atopic eczema and atopy in one birth-cohort study conducted in the United States [4]. Given that low birthweight, prematurity and gestational weight gain are risk factors for childhood asthma [5-7], and low birthweight and premature birth are also risk factors for lower childhood lung function $[8,9]$, high adherence to a Mediterranean diet in pregnancy might be expected to protect against asthma and/or impaired lung function in the offspring. A number of birth-cohort [10-12] and retrospective [13] studies have investigated whether adherence to a Mediterranean diet in pregnancy might protect against the development of asthma and allergies in the offspring, and a recent systematic review concluded that there was some evidence that higher adherence was associated with a lower risk of wheezing in infancy, but evidence for a lower risk of asthma, wheezing and atopic outcomes later in childhood was lacking [14]. Only one prospective study, conducted in Menorca, followed the children to school age [10] and none examined associations with lung function. As a Mediterranean diet is rich in antioxidants, we might expect any beneficial effects of high adherence to a Mediterranean diet on childhood outcomes to be greatest among offspring of mothers who smoked in pregnancy, since tobacco smoke is a source of oxidative stress [15], and that high adherence to a Mediterranean diet would attenuate the detrimental effects of maternal smoking.

In a large UK population-based birth cohort, we have investigated whether greater adherence to a Mediterranean diet in pregnancy is associated with a reduced risk of asthma and other atopic outcomes and with higher lung function in the offspring at school age.

\section{Methods}

\section{Participants}

The Avon Longitudinal Study of Parents and Children (ALSPAC) is a population-based birth cohort which recruited 14541 predominantly white pregnant women resident in Avon, UK with expected dates of delivery April 1, 1991 to December 31, 1992. These pregnancies resulted in 13972 singleton or twin children who were alive at 1 year of age. The cohort has been followed since birth with annual questionnaires and, since age 7 years, with objective measures in annual research clinics. The study protocol has been described previously $[16,17]$. The study website contains details of all the data that are available through a fully searchable data dictionary and variable search tool: www.bristol.ac.uk/alspac/ researchers/our-data/. Ethics approval was obtained from the ALSPAC ethics and law committee (IRB 00003312) and the local National Health Service research ethics committees. Informed consent for the use of data collected via questionnaires and clinics was obtained from participants following the recommendations of the ALSPAC ethics and law committee at the time.

\section{Exposure assessment}

Data on maternal diet in pregnancy were collected by a food frequency questionnaire (FFQ) at 32 weeks' gestation, covering all the main foods consumed in Britain at the time [18]. This FFQ was based on the one used by YARNELL et al. [19] in a British population, which has been validated against weighed dietary records, and modified in the light of a more recent weighed dietary survey [18]. It has been shown to produce mean nutrient intakes for the mothers [18] that were similar to those obtained for women in the British National Diet and Nutritional survey for adults [20,21].

The questionnaire asked about current weekly frequency of consumption of 43 food groups and food items, with the possibility for respondents to tick one of the following options: never or rarely, once in 2 weeks, 1-3 times a week, 4-7 times a week, more than once a day.

More detailed questions were asked about daily consumption of a further eight basic foods (including the number of spoons of sugar, cups of coffee and cups of tea, per day). The FFQ was used to estimate total energy intake and daily nutrient intake, by multiplying the daily frequency of consumption of a food by the nutrient content [22] of a standard portion [23] of that food, and summing this for all the foods consumed. Information on portion size was not collected. In order to apply quantitative meaning to the frequency categories, the data were numerically transformed into times per week as follows: $0,0.5,2,5.5$ and 10 times per week. The number of slices of bread consumed each day on average was recorded separately and the amount of milk consumed was estimated from the number of cups of white tea/coffee consumed per day and the frequency of breakfast cereal, milky puddings and milk drinks consumed per week. 
A Mediterranean diet score was based on that devised by CHATzi et al. [10] for pregnant women, which was adapted from the original Mediterranean diet score by Trichopoulou et al. [1]. Chatzi et al. included dairy products as beneficial, rather than detrimental, and did not include alcohol. The score is based on the median weekly intake of six beneficial food groups (vegetables, legumes, fruits and nuts, cereal, fish and dairy) and one detrimental food group (meat) (supplementary table S1 presents a detailed description of the food groups from the FFQ contributing to each component of the score, and the median weekly consumption in ALSPAC women). Women whose consumption of the beneficial food groups was above the median were assigned a value of 1 , and those below were assigned a value of 0 . Conversely, for the detrimental food group, consumption below the median was assigned a value of 1 , and above the median was assigned a value of 0 . The seven food group values were then summed together to obtain a score which ranged from 0 to 7 , with a higher score representing greater adherence to a Mediterranean-style diet.

\section{Outcome assessment}

Current doctor-diagnosed asthma was defined in children at 7.5 years (primary outcome) if mothers responded positively to the question "Has a doctor ever actually said that your study child has asthma?" and to one or both of the questions "Has your child had any of the following in the past 12 months: wheezing with whistling; asthma?".

Current wheezing, eczema and hay fever in children at 7.5 years were defined by a positive answer to the question: "Has your child had any of the following in the past 12 months: wheezing with whistling; eczema; hay fever?".

Atopy at 7 years was defined as a positive reaction (maximum diameter of any detectable weal) to Dermatophagoides pteronyssinus, cat or grass (after subtracting positive saline reactions from histamine and allergen weals, and excluding children unreactive to $1 \%$ histamine).

Lung function was measured by spirometry (Vitalograph 2120; Vitalograph, Buckingham, UK) at age 8.5 years after withholding short-acting bronchodilators for $\geqslant 6 \mathrm{~h}$ and long-acting bronchodilators and theophyllines for $\geqslant 24 \mathrm{~h}$. The best of three reproducible flow-volume curves was used to measure forced expiratory volume in $1 \mathrm{~s}\left(\mathrm{FEV}_{1}\right)$, forced vital capacity $(\mathrm{FVC})$ and maximal mid-expiratory flow (forced expiratory flow at $25-75 \%$ of $\left.\mathrm{FVC}\left(\mathrm{FEF}_{25-75 \%}\right)\right)$, which were further transformed to age-, height- and sex-adjusted standard deviation units [24]. The tests adhered to American Thoracic Society (ATS) criteria for standardisation and reproducibility of flow-volume measurement [25], with the exception of ATS recommendations for duration of expiration [26]; as many children did not fulfil forced expiratory time $>6 \mathrm{~s}$ end-of-test criteria, a minimal volume change over the final $1 \mathrm{~s}$ was used. Additionally, lung function was measured at 15 years in 3549 ALSPAC children.

\section{Potential confounders}

We selected potential confounding factors which are known (from existing literature) to be associated with one or more of the outcomes of interest [27, 28]. These included maternal age at delivery, sex of child, multiple pregnancy, season of birth, maternal history of atopic diseases (hay fever, asthma, eczema, allergies or attacks of wheezing with whistling on the chest or attacks of breathlessness in the past 2 years), parity, highest educational qualification in UK schools (Certificate of Secondary Education, vocational, Ordinary level, Advanced level, degree), housing tenure, financial difficulties, ethnicity, breastfeeding duration and maternal factors during pregnancy (smoking status, anxiety score (Crown-Crisp Experiential Index) [29], paracetamol use, antibiotic use, infections (urinary infection, influenza, rubella, thrush, genital herpes, other), supplement use (iron, zinc, calcium, folic acid, vitamins, "others") and total energy intake $\left(\mathrm{kJ}^{\mathrm{d}} \mathrm{day}^{-1}\right)$ ). Smoking status was categorised as the maximum exposure during pregnancy (never, passive

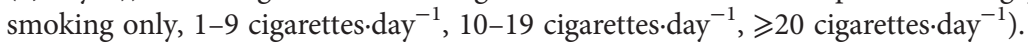

\section{Statistical analyses}

We compared the distributions of child and maternal variables across the maternal Mediterranean diet score categories $(\geqslant 4$ versus $\leqslant 3$, as done previously by CHATZI et al. [10]) using t-tests for differences in continuous variables and Chi-squared tests for differences in categorical variables. Logistic regression, multinomial logistic regression and linear regression were used to analyse relations between the maternal Mediterranean diet score in pregnancy and binary, categorical and continuous outcomes, respectively. We analysed the maternal Mediterranean diet score first as a binary variable (i.e. $\geqslant 4$ and $\leqslant 3[10]$ ) using the lower category as reference, and second as a continuous variable to test for linear trend (i.e. per increasing score-unit effect). For all regression analyses, two stages of adjustment were used. In model 1 we adjusted for total energy intake only. In model 2 we adjusted additionally for all potential confounders listed above.

When evidence for associations persisted, we considered other factors which could be considered as potential mediators of associations between maternal Mediterranean diet in pregnancy and childhood 
outcomes, namely, prematurity [3, 7, 9], impaired fetal growth [2, 3, 5, 8], maternal obesity (which can be viewed either as confounder or mediator) and weight gain $[3,6]$ and offspring obesity [30, 31]. Therefore, we adjusted additionally for maternal pre-pregnancy body mass index (BMI) (self-reported, categorised according to World Health Organization categories [32]), gestational age at delivery, birthweight $(<2500$, $2500-2999,3000-3499,3500-3999, \geqslant 4000 \mathrm{~g}[5,33]$ ), maternal weight gain during pregnancy (categorised in quartiles) (all abstracted from obstetric records) and child's BMI at 7 years (based on measured height and weight at clinic, categorised into $<15.00,15.00-17.49,17.50-20.49, \geqslant 20.50 \mathrm{~kg} \cdot \mathrm{m}^{-2}$ [33]), using separate models (i.e. one model for each potential mediator), to investigate potential mediation (supplementary figure S1 shows a directed acyclic graph). As a Mediterranean diet is rich in antioxidants, we might expect any beneficial effects on childhood outcomes to be greatest among offspring of mothers who smoked in pregnancy, since tobacco smoke is a source of oxidative stress [15]. We therefore stratified the dietary analyses by maternal smoking history (dichotomised) to explore potential effect modification by smoking and tested for interaction. In addition, we explored whether the association between maternal smoking in pregnancy and $\mathrm{FEF}_{25-75 \%}$, previously reported in ALSPAC [34], was modified by Mediterranean diet score (dichotomised).

As sensitivity analyses, we repeated analyses after exclusion of mothers with implausible energy intakes, defined as total daily energy intake below the bottom $5 \%$ (i.e. $1028 \mathrm{kcal} \cdot \mathrm{day}^{-1}$ ) or above the top $5 \%$ (i.e. $2560 \mathrm{kcal} \cdot \mathrm{day}^{-1}$ ). To correct for potential loss-to-follow-up bias, we used inverse probability weighting and assigned to each woman a weight that is the inverse of the probability of her selection for given values of covariates (further details are given in the supplementary material) [35]. To investigate potential nonlinear effects, we repeated our analyses of the associations between the maternal Mediterranean diet score and childhood outcomes, first considering the Mediterranean diet score in two categories, comparing women with a score of 6-7 to women with a score $0-5$, and second considering the Mediterranean diet score in four categories (0-1 (reference category), 2-3, 4-5 and 6-7).

All statistical analyses were performed using Stata (version 12.1; StataCorp, College Station, TX, USA).

\section{Results}

Of the 13972 singleton or twin children alive at 1 year of age, information on maternal diet was available for 11993, of whom there was information on at least one of the outcomes of interest for 8907 (supplementary figure S2). Characteristics of the 8907 mother-child pairs included in the analyses, and those of the 3086 mother-child pairs with information on maternal diet who were excluded because of missing outcome data at 7-9 years (i.e. lost to follow-up), are compared in supplementary table S2.

Women in the higher category of Mediterranean diet score during pregnancy were older and more educated than women in the lower category. They were more likely to give birth in winter or spring, to breastfeed for $\geqslant 3$ months, to have an owned/mortgaged house and to use supplements during pregnancy. They were less likely to have financial difficulties, to have a high anxiety score, to smoke or to use paracetamol during pregnancy. In addition, they had a lower pre-pregnancy BMI, higher total energy intake and gained more weight during pregnancy. Their offspring were more likely to have weighed more at birth and less likely to have a high BMI at 7 years (table 1).

After controlling for confounders, maternal Mediterranean diet score (whether analysed as a binary or continuous variable), was not associated with asthma, wheeze, eczema, hayfever or atopy (table 2). When we analysed the associations between the maternal Mediterranean diet score and childhood lung function at 8-9 years after controlling for total energy intake only, strong evidence was found for positive

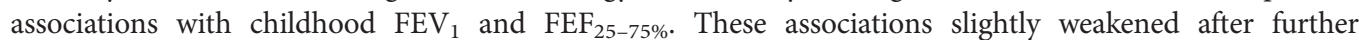
adjustment for potential confounders, but evidence for a positive association with childhood $\mathrm{FEF}_{25-75 \%}$ persisted when comparing higher versus lower maternal Mediterranean diet score (difference in age-, height- and sex-adjusted standard deviation units 0.06 , 95\% CI 0.01-0.12; p-value 0.03) (table 3). When we analysed the relationship between Mediterranean diet score and childhood lung function at 15 years, the per-unit increase effect estimates for $\mathrm{FEF}_{25-75 \%}$ were similar to those observed at 8 years (supplementary table S3); however, given the smaller sample size, associations were no longer conventionally significant.

Additional separate adjustment for maternal pre-pregnancy BMI, gestational age at delivery, birthweight, maternal weight gain during pregnancy and child's BMI at 7 years did not alter the main findings (data not shown), and therefore no further formal mediation analysis was conducted. Excluding mothers with implausible energy intakes did not alter the main findings, nor did the inverse probability weighting analysis (data not shown).

When we stratified the analyses of Mediterranean diet and lung function by maternal smoking in pregnancy, maternal Mediterranean diet was positively associated with childhood $\mathrm{FEF}_{25-75 \%}$ among non-/ 
TABLE 1 Characteristics of mothers and offspring who had information on at least one of the outcomes of interest (wheeze, asthma, atopy, eczema, hayfever, total lgE, lung function) by maternal Mediterranean diet score in pregnancy $(n=8907)$

\begin{tabular}{|c|c|c|c|}
\hline & \multicolumn{2}{|c|}{ Mediterranean diet score } & \multirow[t]{2}{*}{ p-value ${ }^{\#}$} \\
\hline & $0-3$ & 4-7 & \\
\hline Subjects $\mathrm{n}$ & 3475 & 5432 & \\
\hline Mother's age years & $28.1 \pm 4.7$ & $29.4 \pm 4.5$ & $<0.001$ \\
\hline \multicolumn{4}{|l|}{ Parity (living children) } \\
\hline 0 & 45.2 & 45.7 & \multirow[t]{3}{*}{0.83} \\
\hline 1 & 36.3 & 35.7 & \\
\hline$\geqslant 2$ & 18.5 & 18.6 & \\
\hline \multicolumn{4}{|l|}{ Sex of child } \\
\hline Male & 50.0 & 51.9 & \multirow[t]{2}{*}{0.08} \\
\hline Female & 50.0 & 48.1 & \\
\hline \multicolumn{4}{|l|}{ Multiple pregnancy } \\
\hline Singleton & 97.5 & 97.6 & \multirow[t]{2}{*}{0.66} \\
\hline Twin & 2.5 & 2.4 & \\
\hline \multicolumn{4}{|l|}{ Season of birth } \\
\hline Winter & 15.9 & 16.3 & \multirow[t]{4}{*}{$<0.001$} \\
\hline Spring & 25.1 & 28.3 & \\
\hline Summer & 30.0 & 30.1 & \\
\hline Autumn & 29.0 & 25.4 & \\
\hline \multicolumn{4}{|l|}{ Breastfeeding duration } \\
\hline Never & 28.6 & 16.5 & \multirow[t]{4}{*}{$<0.001$} \\
\hline$<3$ months & 35.3 & 29.2 & \\
\hline $3-6$ months & 12.2 & 14.8 & \\
\hline$\geqslant 6$ months & 23.9 & 39.5 & \\
\hline \multicolumn{4}{|l|}{ Mother's educational level } \\
\hline Certificate of Secondary Education & 21.3 & 11.6 & \multirow[t]{5}{*}{$<0.001$} \\
\hline Vocational & 11.7 & 7.3 & \\
\hline Ordinary level & 38.7 & 33.4 & \\
\hline Advanced level & 19.4 & 28.7 & \\
\hline Degree & 8.9 & 19.0 & \\
\hline \multicolumn{4}{|l|}{ Maternal ethnicity } \\
\hline White & 98.0 & 98.3 & \multirow[t]{2}{*}{0.38} \\
\hline Non-white & 2.0 & 1.7 & \\
\hline \multicolumn{4}{|l|}{ Housing tenure } \\
\hline Owned/mortgaged & 78.2 & 87.3 & $<0.001$ \\
\hline Council rented & 14.2 & 6.4 & \\
\hline Non-council rented & 7.6 & 6.3 & \\
\hline Financial difficulties & & & \\
\hline Yes & 19.8 & 15.4 & $<0.001$ \\
\hline Maternal history of atopic diseases & & & \\
\hline Yes & 69.1 & 67.9 & 0.24 \\
\hline Maternal anxiety score in pregnancy & & & \\
\hline $0-9$ & 18.4 & 23.1 & $<0.001$ \\
\hline $10-14$ & 25.0 & 26.2 & \\
\hline $15-20$ & 25.7 & 26.1 & \\
\hline$\geqslant 20$ & 31.0 & 24.7 & \\
\hline Maximum maternal tobacco exposur & & & \\
\hline None & 21.5 & 29.7 & $<0.001$ \\
\hline Passive only & 44.7 & 46.7 & \\
\hline $1-9$ cigarette $\cdot$ day $^{-1}$ & 7.9 & 7.9 & \\
\hline $10-19$ cigarette $\cdot$ day $^{-1}$ & 14.1 & 9.6 & \\
\hline$\geqslant 20$ cigarette $\cdot$ day $^{-1}$ & 11.8 & 6.0 & \\
\hline Maternal paracetamol use during pr & & & \\
\hline Yes & 64.6 & 61.0 & 0.001 \\
\hline Maternal antibiotic use during pregr & & & \\
\hline Yes & 16.0 & 16.2 & 0.81 \\
\hline Maternal dietary supplement use du & & & \\
\hline Yes & 54.4 & 58.4 & $<0.001$ \\
\hline Maternal infections in pregnancy & & & \\
\hline Yes & 45.1 & 46.2 & 0.33 \\
\hline
\end{tabular}




\begin{tabular}{|c|c|c|c|}
\hline & \multicolumn{2}{|c|}{ Mediterranean diet score } & \multirow[t]{2}{*}{ p-value ${ }^{\#}$} \\
\hline & $0-3$ & 4-7 & \\
\hline Total energy intake kcal-day ${ }^{-1}$ & $1600 \pm 451$ & $1826 \pm 459$ & $<0.001$ \\
\hline \multicolumn{4}{|c|}{ Maternal pre-pregnancy BMI $\mathrm{kg} \cdot \mathrm{m}^{-2}$} \\
\hline$<18.50$ & 4.1 & 4.4 & $<0.001$ \\
\hline $18.50-24.99$ & 71.4 & 77.8 & \\
\hline $25.00-29.99$ & 17.4 & 13.7 & \\
\hline$\geqslant 30.00$ & 7.1 & 4.1 & \\
\hline \multicolumn{4}{|l|}{ Birthweight g } \\
\hline$<2500$ & 5.0 & 3.8 & 0.006 \\
\hline $2500-2999$ & 14.6 & 13.3 & \\
\hline $3000-3499$ & 35.8 & 35.3 & \\
\hline $3500-3999$ & 31.9 & 34.0 & \\
\hline$\geqslant 4000$ & 12.7 & 13.7 & \\
\hline Gestational age weeks & $39.4 \pm 1.8$ & $39.5 \pm 1.8$ & 0.13 \\
\hline \multicolumn{4}{|l|}{ Child's BMI at 7 years $\mathrm{kg} \cdot \mathrm{m}^{-2}$} \\
\hline$<15.00$ & 28.0 & 28.1 & 0.01 \\
\hline $15.00-17.49$ & 51.7 & 53.0 & \\
\hline $17.50-20.49$ & 15.2 & 15.2 & \\
\hline$\geqslant 20.50$ & 5.2 & 3.6 & \\
\hline \multicolumn{4}{|c|}{ Maternal weight gain during pregnancy } \\
\hline Quartile 1 (<9.7 kg) & 27.8 & 23.7 & 0.001 \\
\hline Quartile $2(9.7-12.5 \mathrm{~kg})$ & 23.8 & 25.5 & \\
\hline Quartile $3(12.5-15.5 \mathrm{~kg})$ & 25.1 & 25.7 & \\
\hline Quartile 4 ( $\geqslant 15.5 \mathrm{~kg}$ ) & 23.4 & 25.1 & \\
\hline
\end{tabular}

Data are presented as mean \pm SD or \%, unless otherwise stated. Ig: immunoglobulin; BMI: body mass index.

\#: Chi-squared tests were used for categorical variables, and t-tests were used for continuous variables.

passive smokers, but not among active smokers, but no evidence for a statistically significant interaction was found (table 4). Conversely, when we stratified the negative association between maternal smoking in pregnancy and $\mathrm{FEF}_{25-75 \%}$ by Mediterranean diet score (dichotomised), there was no evidence of attenuation of the association by higher adherence to a Mediterranean diet (data not shown).

TABLE 2 Associations between maternal Mediterranean diet score during pregnancy and asthma, wheeze, eczema, hay fever and atopy in the offspring $(n=8629)$

\begin{tabular}{|c|c|c|c|c|c|}
\hline & \multirow[t]{2}{*}{ Subjects } & \multicolumn{4}{|c|}{ Mediterranean diet score } \\
\hline & & 4-7 versus $0-3$ & p-value & Per-unit increase & $\overline{p-t r e n d}$ \\
\hline Asthma & 7634 & & & & \\
\hline Model $1^{\#}$ & & $0.94(0.81-1.09)$ & 0.41 & $0.97(0.92-1.01)$ & 0.15 \\
\hline Model $2^{\text {n }}$ & & $1.03(0.88-1.20)$ & 0.71 & $1.00(0.95-1.05)$ & 0.93 \\
\hline Wheeze & 7719 & & & & \\
\hline Model $1^{\#}$ & & $1.02(0.88-1.19)$ & 0.80 & $1.01(0.96-1.06)$ & 0.84 \\
\hline Model 2" & & $1.04(0.89-1.22)$ & 0.62 & $1.01(0.96-1.07)$ & 0.63 \\
\hline Eczema & 7705 & & & & \\
\hline Model $1^{\#}$ & & $1.13(0.99-1.29)$ & 0.07 & $1.03(0.99-1.07)$ & 0.18 \\
\hline Model 2" & & $1.10(0.96-1.26)$ & 0.18 & $1.01(0.97-1.06)$ & 0.55 \\
\hline Hay fever & 7685 & & & & \\
\hline Model $1^{\#}$ & & $1.00(0.85-1.18)$ & 0.99 & $1.01(0.96-1.07)$ & 0.72 \\
\hline Model $2^{\pi}$ & & $0.97(0.81-1.15)$ & 0.69 & $1.00(0.94-1.06)$ & 0.97 \\
\hline Atopy & 6078 & & & & \\
\hline Model $1^{\#}$ & & $1.03(0.90-1.17)$ & 0.66 & $1.03(0.98-1.07)$ & 0.23 \\
\hline Model $2^{\text {q }}$ & & $0.94(0.82-1.07)$ & 0.34 & $0.99(0.95-1.04)$ & 0.81 \\
\hline \multicolumn{6}{|c|}{ 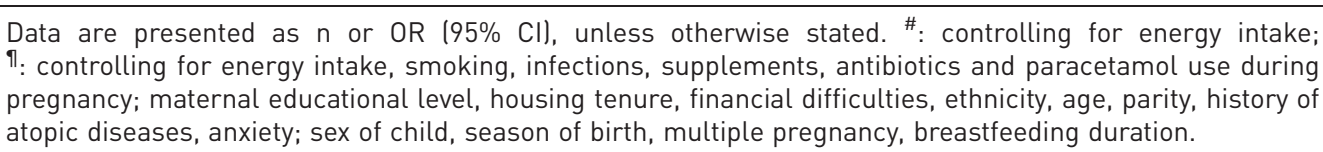 } \\
\hline
\end{tabular}


TABLE 3 Associations between maternal Mediterranean diet score during pregnancy (binary and continuous) and $\mathrm{FEV}_{1}, \mathrm{FVC}$ and $\mathrm{FEF}_{25-75 \%}$ in the offspring ( $\mathrm{n}=6120$ )

\begin{tabular}{|c|c|c|c|c|c|}
\hline & \multirow[t]{2}{*}{ Subjects $\mathbf{n}$} & \multicolumn{4}{|c|}{ Mediterranean diet score } \\
\hline & & 4-7 versus $0-3$ & p-value & Per unit increase & p-trend \\
\hline $\mathrm{FEV}_{1}$ & 6026 & & & & \\
\hline Model $1^{\#}$ & & $0.07(0.01-0.12)$ & 0.01 & $0.03(0.01-0.04)$ & 0.005 \\
\hline Model $2^{\pi}$ & & $0.05(-0.01-0.10)$ & 0.11 & $0.02(0.00-0.04)$ & 0.06 \\
\hline FVC & 6120 & & & & \\
\hline Model $1^{\#}$ & & $0.03(-0.03-0.08)$ & 0.36 & $0.01(0.00-0.03)$ & 0.12 \\
\hline Model 2ף & & $0.01(-0.05-0.06)$ & 0.78 & $0.01(-0.01-0.03)$ & 0.38 \\
\hline $\mathrm{FEF}_{25-75 \%}$ & 6120 & & & & \\
\hline Model $1^{\#}$ & & $0.08(0.02-0.13)$ & 0.005 & $0.02(0.01-0.04)$ & 0.01 \\
\hline Model 2 & & $0.06(0.01-0.12)$ & 0.03 & $0.02(0.00-0.04)$ & 0.06 \\
\hline
\end{tabular}

Data are presented as $\mathrm{n}$ or $\beta(95 \% \mathrm{Cl})$, unless otherwise stated. $\mathrm{FEV}_{1}$ : forced expiratory volume in $1 \mathrm{~s}$; FVC: forced vital capacity; $\mathrm{FEF}_{25-75 \%}$ : maximal mid-expiratory flow (forced expiratory flow at $25-75 \%$ of $\mathrm{FVC}$ ); $\beta$ : difference in age-, height- and sex-adjusted standard deviation units. \#: controlling for energy intake; ${ }^{\text {: }}$ controlling for energy intake, smoking, infections, supplements, antibiotics and paracetamol use during pregnancy; maternal educational level, housing tenure, financial difficulties, ethnicity, age, parity, maternal history of atopic diseases, anxiety score; sex of child, season of birth, multiple pregnancy, breastfeeding duration.

When analyses of the associations between the maternal Mediterranean diet score and childhood $\mathrm{FEV}_{1}$ and $\mathrm{FEF}_{25-75 \%}$ were repeated, considering the Mediterranean diet score in two categories (0-5 (reference category) and 6-7) or in four categories (0-1 (reference category), 2-3, 4-5 and 6-7) to investigate the linearity of the association, results were consistent with linear trends (data not shown).

\section{Discussion}

This is the largest observational study to investigate the relationship between Mediterranean diet in pregnancy and childhood respiratory and allergic outcomes. A limitation of the evidence to date is that many studies have assessed maternal diet retrospectively or have only investigated outcomes in infancy. Of two cohort studies which assessed Mediterranean diet during pregnancy and outcomes beyond infancy,

TABLE 4 Associations between maternal Mediterranean diet score during pregnancy and childhood lung function stratified by maternal smoking during pregnancy $(n=6115)$

\begin{tabular}{|c|c|c|c|c|c|}
\hline & \multirow[t]{2}{*}{ Subjects } & \multicolumn{4}{|c|}{ Mediterranean diet score $\beta^{\#}(95 \% \mathrm{CI})$} \\
\hline & & $4-7$ versus $0-3$ & p-value & Per unit increase & p-trend \\
\hline \multicolumn{6}{|l|}{$\mathrm{FEV}_{1}$} \\
\hline Non-/passive smokers & 4479 & $0.05(-0.02-0.11)$ & 0.15 & $0.02(0.00-0.04)$ & 0.10 \\
\hline $\begin{array}{l}\text { Active smokers } \\
\text { p interaction? }\end{array}$ & 1542 & $\begin{array}{c}0.04(-0.07-0.15) \\
0.81\end{array}$ & 0.45 & $\begin{array}{c}0.02(-0.02-0.06) \\
0.96\end{array}$ & 0.29 \\
\hline \multicolumn{6}{|l|}{ FVC } \\
\hline Non-/passive smokers & 4558 & $0.01(-0.05-0.08)$ & 0.71 & $0.01(-0.02-0.03)$ & 0.59 \\
\hline $\begin{array}{l}\text { Active smokers } \\
\text { p interaction }\end{array}$ & 1557 & $\begin{array}{c}0.01(-0.09-0.12) \\
0.69\end{array}$ & 0.80 & $\begin{array}{c}0.02(-0.02-0.05) \\
0.90\end{array}$ & 0.33 \\
\hline \multicolumn{6}{|l|}{$\mathrm{FEF}_{25-75 \%}$} \\
\hline Non-/passive smokers & 4558 & $0.07(0.00-0.13)$ & 0.04 & $0.02(0.00-0.04)$ & 0.05 \\
\hline $\begin{array}{l}\text { Active smokers } \\
\mathrm{p} \text { interaction }\end{array}$ & 1557 & $\begin{array}{c}0.04(-0.07-0.15) \\
0.86\end{array}$ & 0.44 & $\begin{array}{c}0.01(-0.03-0.04) \\
0.68\end{array}$ & 0.70 \\
\hline
\end{tabular}

$\beta$ : difference in age-, height- and sex-adjusted standard deviation units; $F E V_{1}$ : forced expiratory volume in $1 \mathrm{~s}$; FVC: forced vital capacity; $\mathrm{FEF}_{25-75 \%}$ : maximal mid-expiratory flow (forced expiratory flow at $25-75 \%$ of FVC). " : controlling for energy intake, infections, supplements, antibiotics and paracetamol use during pregnancy; maternal educational level, housing tenure, financial difficulties, ethnicity, age, parity, maternal history of atopic diseases, anxiety score; sex of child, season of birth, multiple pregnancy, breastfeeding duration; ": treating smoking as a binary variable and the Mediterranean diet score as either a binary or continuous variable. 
one small study from Menorca $(n=460)$, using the same maternal Mediterranean diet score, reported significant negative associations with wheeze and atopy at 6.5 years [10], but another, larger, study from the US, using a slightly different score $(n=1376)$, found no association with asthma, wheeze or atopy at 3 years [12]. Given the much larger size of ALSPAC, and our null findings for childhood asthma, wheeze and allergic outcomes, we would argue that the weight of current prospective evidence suggests that adherence to a Mediterranean diet in pregnancy is unlikely to reduce the risk of these conditions at school age. However, we found weak evidence that a higher Mediterranean diet score during pregnancy was associated with higher $\mathrm{FEF}_{25-75 \%}$ in the offspring, after controlling for potential confounders. Previous studies have not investigated the relationship between Mediterranean diet in pregnancy and childhood lung function; to the best of our knowledge this is a novel finding.

\section{Mechanisms}

If the association between Mediterranean diet in pregnancy and lung function in the offspring is causal, one plausible explanation is that it is mediated through the high antioxidant content of the fruit, vegetables and cereals in a Mediterranean diet [14]. If this were the case, we would have expected to see an interaction between maternal Mediterranean diet score in pregnancy and maternal smoking on childhood $\mathrm{FEF}_{25-75 \%}$. To our knowledge, this has not been investigated before. We hypothesised, a priori, that a higher Mediterranean diet score in pregnancy might be particularly beneficial if the fetus was exposed to tobacco smoke, by protecting the developing lung from potentially damaging oxidative stress [15]. In fact, there was no association between a Mediterranean diet in pregnancy and lung function among active smokers. On the contrary, an association was only seen among mothers who had not actively smoked in pregnancy. An alternative, post hoc hypothesis could be that benefits are only seen above a certain threshold of adherence to a Mediterranean diet, and we have confirmed that mothers who did not actively smoke in pregnancy had a higher Mediterranean diet score than those who did. Additionally, we found no evidence that the detrimental effects of maternal smoking on childhood $\mathrm{FEF}_{25-75 \%}$ were attenuated by higher adherence to a Mediterranean diet. Apart from its antioxidant properties, a Mediterranean diet may have anti-inflammatory effects [36]. Part of this effect may reflect the anti-inflammatory properties of omega-3 polyunsaturated fatty acids in oily fish. We speculate that this might partly explain the association between a Mediterranean diet in pregnancy and offspring lung function that we observed; a recent trial reported that fish oil derived omega-3 fatty acid supplementation in pregnancy reduced the risk of early childhood wheezing in the offspring [37], and early childhood wheezing is associated with later reductions in lung function [38]. We found no evidence to suggest that the association between maternal Mediterranean diet score and childhood $\mathrm{FEF}_{25-75 \%}$ was mediated by maternal BMI, gestational weight gain or child's BMI, nor by prematurity or low birthweight.

\section{Strengths and limitations}

Strengths of the ALSPAC birth cohort include its population-based prospective design, rich information on numerous potential confounders, detailed phenotypic outcome measurements, and its size, which gave us greater statistical power than the previous birth cohort study that has investigated this research question in offspring of school age [10].

The Mediterranean diet score has been developed in Mediterranean countries and is based on population-specific median values. Thus, it may not be adapted to non-Mediterranean countries such as the UK, in which median intakes of some specific foods may be lower, and potential beneficial effects might be missed. We acknowledge that this might be an explanation for why an association was found between the maternal Mediterranean diet and childhood asthma in children from Menorca (i.e. a Mediterranean population) [10] and not in children in the USA [12] or in ALSPAC children. However, the fact that similar results were observed in our data when the Mediterranean diet score was studied as a binary (above versus below median, highest categories versus low or medium score) or as a continuous variable makes this possibility less likely. A previous study of maternal dietary patterns in pregnancy in relation to childhood respiratory outcomes has been conducted in ALSPAC, using principal component analysis (PCA) to derive dietary patterns [39]. That study showed that dietary patterns in pregnancy, including a "health-conscious" pattern (which had some similarities to a Mediterranean diet), did not predict asthma and related outcomes in the offspring after controlling for confounders. However, data-driven methods such as PCA are population-specific, and using a priori approaches such as the Mediterranean diet score is more relevant in terms of public health. Other a priori approaches such as the Alternate Healthy Eating Index (AHEI) score, which is based on international guidelines and has been adapted for pregnant women (AHEI-P) [40], may be more adapted to non-Mediterranean populations; however, given the lack of information on some specific AHEI-P food/nutrient items in ALSPAC's FFQ, e.g. trans-fat and whole grains (although partly covered by cereals), it was not applicable in ALSPAC pregnant women. 
Although the FFQ that we used had not been formally calibrated against other instruments such as diet diaries, it was based on the one used by YARNELL et al. [19] which has been validated against weighed dietary records, and modified in the light of a more recent weighed dietary survey [18]. Although the limitations of the FFQ method are well known, reproducibility and validity of FFQs have been studied and found to be relatively good overall [41]. While there might have been some misclassification of dietary exposures (e.g. the ALSPAC FFQ did not allow us to distinguish between white and wholegrain bread, between white and brown rice and between red and processed meat; and bread consumption was assessed differently compared to other food groups, and thus may have been overestimated), this is likely to have been non-differential with respect to the outcomes of interest, and would be expected to bias effect estimates towards the null; in other words, the magnitude of associations may have been underestimated, and small or modest effects may have been missed. The possibility that the association between Mediterranean diet in pregnancy and offspring lung function might be explained by uncontrolled or residual confounding cannot be ruled out, especially given that the Mediterranean diet score is highly correlated with social and lifestyle factors. However, we think that this is unlikely, as we controlled for numerous potential confounders in the analyses. Another limitation is that child's Mediterranean diet score was not available in ALSPAC and hence we cannot rule out potential confounding by postnatal diet. However, since most findings are null, childhood diet would have to be acting as a negative confounder for significant effects of maternal Mediterranean diet to appear on adjustment, which seems unlikely. As with any longitudinal study, we cannot rule out the possibility that exclusion of mother-child pairs without complete information might have biased our findings. However, it could be argued that, for our results for the Mediterranean diet score and childhood lung function to be totally spurious in those included in our analysis (and for the associations to be truly null in the population as a whole), associations in the excluded mother-child pairs would have to be at least of equal magnitude in the opposite direction, which seems unlikely. Furthermore, loss to follow-up bias has been shown to only slightly modify associations in longitudinal studies, including in ALSPAC [42], and the results of our inverse probability weighting analysis confirmed that loss to follow-up is unlikely to have biased our results. In view of the multiple analyses undertaken, we cannot exclude the possibility that the associations between Mediterranean diet in pregnancy and offspring lung function occurred by chance; hence they should be interpreted with caution and require replication in another birth cohort study. Given the a priori nature of the general hypothesis being tested (i.e. a beneficial effect of a Mediterranean diet), and the fact that some outcomes of interest were highly correlated, it did not seem appropriate to correct for multiple testing.

\section{Conclusions}

We found weak evidence that greater adherence to a Mediterranean diet in pregnancy is associated with higher small airway function in the offspring, but is not associated with a reduced risk of asthma or other allergic outcomes. Further studies in school-aged children are needed to confirm these results.

Acknowledgements: We are extremely grateful to all the families who took part in this study, the midwives for their help in recruiting them, and the whole ALSPAC team, which includes interviewers, computer and laboratory technicians, clerical workers, research scientists, volunteers, managers, receptionists and nurses. This paper is dedicated to the memory of our late colleague John Henderson.

Author contributions: A. Bédard, K. Northstone and S.O. Shaheen conceived the study and drafted the manuscript. All authors were involved in the analysis strategy, K. Northstone gave advice on the dietary data, and A. Bédard performed the statistical analyses. A.J. Henderson was responsible for all clinical respiratory and allergy data collection. All authors participated in the interpretation of the findings, reviewed the manuscript and revised it critically before submission. A. Bédard, K. Northstone and S.O. Shaheen have seen and approved the final version of the manuscript.

Conflict of interest: A. Bédard has nothing to disclose. K. Northstone has nothing to disclose. A.J. Henderson reports grants from Medical Research Council and Wellcome, during the conduct of the study. S.O. Shaheen has nothing to disclose.

Support statement: The UK Medical Research Council and Wellcome (grant ref: 102215/2/13/2) and the University of Bristol provide core support for ALSPAC. This publication is the work of the authors and Seif O. Shaheen will serve as guarantor for the contents of this paper. A comprehensive list of grants funding is available on the ALSPAC website (www.bristol.ac.uk/alspac/external/documents/grant-acknowledgements.pdf). This research was specifically funded by the MRC (Grant ref: G0401540/73080). A. Bédard was funded by a European Respiratory Society Long-term Research Fellowship (Fellowship ID LTRF 2015-5838). Funding information for this article has been deposited with the Crossref Funder Registry.

\section{References}

1 Trichopoulou A, Costacou T, Bamia C, et al. Adherence to a Mediterranean diet and survival in a Greek population. N Engl J Med 2003; 348: 2599-2608.

2 Timmermans S, Steegers-Theunissen RP, Vujkovic M, et al. The Mediterranean diet and fetal size parameters: the Generation R Study. Br J Nutr 2012; 108: 1399-1409. 
3 Assaf-Balut C, García de la Torre N, Durán A, et al. A Mediterranean diet with additional extra virgin olive oil and pistachios reduces the incidence of gestational diabetes mellitus (GDM): a randomized controlled trial: The St. Carlos GDM prevention study. PLoS One 2017; 12: e0185873.

4 Kumar R, Ouyang F, Story RE, et al. Gestational diabetes, atopic dermatitis, and allergen sensitization in early childhood. J Allergy Clin Immunol 2009; 124: 1031-1038.

5 Xu X-F, Li Y-J, Sheng Y-J, et al. Effect of low birth weight on childhood asthma: a meta-analysis. BMC Pediatr 2014; 14: 275.

6 Forno E, Young OM, Kumar R, et al. Maternal obesity in pregnancy, gestational weight gain, and risk of childhood asthma. Pediatrics 2014; 134: e535-e546.

7 Been J V, Lugtenberg MJ, Smets E, et al. Preterm birth and childhood wheezing disorders: a systematic review and meta-analysis. PLoS Med 2014; 11: e1001596.

8 Örtqvist AK, Ullemar V, Lundholm C, et al. Fetal growth and childhood lung function in the Swedish Twin Study on Prediction and Prevention of Asthma. Ann Am Thorac Soc 2017; 14: 1147-1153.

9 Kotecha SJ, Watkins WJ, Paranjothy S, et al. Effect of late preterm birth on longitudinal lung spirometry in school age children and adolescents. Thorax 2012; 67: 54-61.

10 Chatzi L, Torrent M, Romieu I, et al. Mediterranean diet in pregnancy is protective for wheeze and atopy in childhood. Thorax 2008; 63: 507-513.

11 Chatzi L, Garcia R, Roumeliotaki T, et al. Mediterranean diet adherence during pregnancy and risk of wheeze and eczema in the first year of life: INMA (Spain) and RHEA (Greece) mother-child cohort studies. Br J Nutr 2013; 110: 2058-2068.

12 Lange NE, Rifas-Shiman SL, Camargo CA, et al. Maternal dietary pattern during pregnancy is not associated with recurrent wheeze in children. J Allergy Clin Immunol 2010; 126: 250-255.

13 de Batlle J, Garcia-Aymerich J, Barraza-Villarreal A, et al. Mediterranean diet is associated with reduced asthma and rhinitis in Mexican children. Allergy 2008; 63: 1310-1316.

14 Castro-Rodriguez JA, Garcia-Marcos L. What are the effects of a Mediterranean diet on allergies and asthma in children? Front Pediatr 2017; 5: 72.

15 Vardavas CI, Flouris AD, Tsatsakis A, et al. Does adherence to the Mediterranean diet have a protective effect against active and passive smoking? Public Health 2011; 125: 121-128.

16 Boyd A, Golding J, Macleod J, et al. Cohort profile: the "children of the 90s" - the index offspring of the Avon Longitudinal Study of Parents and Children. Int J Epidemiol 2013; 42: 111-127.

17 Fraser A, Macdonald-Wallis C, Tilling K, et al. Cohort profile: The Avon Longitudinal Study of Parents and Children: ALSPAC mothers cohort. Int J Epidemiol 2013; 42: 97-110.

18 Rogers I, Emmett P. Diet during pregnancy in a population of pregnant women in South West England. ALSPAC Study Team. Avon Longitudinal Study of Pregnancy and Childhood. Eur J Clin Nutr 1998; 52: 246-250.

19 Yarnell JW, Fehily AM, Milbank JE, et al. A short dietary questionnaire for use in an epidemiological survey: comparison with weighed dietary records. Hum Nutr Appl Nutr 1983; 37: 103-112.

20 Gregory J, Foster K, Tyler H, et al. Classification of types of diet. In: The Dietary and Nutritional Survey of British Adults. Office of Population Censuses and Surveys. London, HMSO, 1990.

21 Ministry of Agriculture, Fisheries and Food. The Dietary and Nutritional Survey of British Adults: Further Analysis. London, HMSO, 1994.

22 McCance and Widdowson's The Composition of Foods. 5th Edn. Cambridge, Royal Society of Chemistry/Food Standards Agency, 1991

23 Ministry of Agriculture and Food. Food Portion Sizes. London, HMSO, 1991.

24 Chinn S, Rona RJ. Height and age adjustment for cross sectional studies of lung function in children aged 6-11 years. Thorax 1992; 47: 707-714.

25 Standardization of spirometry, 1994 update. American Thoracic Society. Am J Respir Crit Care Med 1995; 152: 1107-1136.

26 Arets HGM, Brackel HJL, van der Ent CK. Forced expiratory manoeuvres in children: do they meet ATS and ERS criteria for spirometry? Eur Respir J 2001; 18: 655-660.

27 Nurmatov U, Nwaru BI, Devereux G, et al. Confounding and effect modification in studies of diet and childhood asthma and allergies. Allergy 2012; 67: 1041-1059.

28 Ullemar V, Lundholm C, Almqvist C. Twins' risk of childhood asthma mediated by gestational age and birthweight. Clin Exp Allergy 2015; 45: 1328-1336.

29 Birtchnell J, Evans C, Kennard J. The total score of the Crown-Crisp Experiential Index: a useful and valid measure of psychoneurotic pathology. Br J Med Psychol 1988; 61: 255-266.

30 Litonjua AA, Gold DR. Asthma and obesity: common early-life influences in the inception of disease. $J$ Allergy Clin Immunol 2008; 121: 1075-1084.

31 Chatzi L, Rifas-Shiman SL, Georgiou V, et al. Adherence to the Mediterranean diet during pregnancy and offspring adiposity and cardiometabolic traits in childhood. Pediatr Obes 2017; 12: Suppl. 1, 47-56.

32 World Health Organization (WHO). Global Database on Body-Mass Index, BMI classification. Date last accessed: December 21, 2019. www.euro.who.int/en/health-topics/disease-prevention/nutrition/a-healthy-lifestyle/bodymass-index-bmi

33 Shaheen SO, Newson RB, Ring SM, et al. Prenatal and infant acetaminophen exposure, antioxidant gene polymorphisms, and childhood asthma. J Allergy Clin Immunol 2010; 126: 1141-1148.

34 Henderson AJ, Newson RB, Rose-Zerilli M, et al. Maternal Nrf2 and gluthathione-S-transferase polymorphisms do not modify associations of prenatal tobacco smoke exposure with asthma and lung function in school-aged children. Thorax 2010; 65: 897-902.

35 Hernán MA, Hernández-Díaz S, Robins JM. A structural approach to selection bias. Epidemiology 2004; 15: 615-625

36 Fung TT, McCullough ML, Newby PK, et al. Diet-quality scores and plasma concentrations of markers of inflammation and endothelial dysfunction. Am J Clin Nutr 2005; 82: 163-173.

37 Bisgaard H, Stokholm J, Chawes BL, et al. Fish oil-derived fatty acids in pregnancy and wheeze and asthma in offspring. N Engl J Med 2016; 375: 2530-2539.

38 Duijts L, Granell R, Sterne JAC, et al. Childhood wheezing phenotypes influence asthma, lung function and exhaled nitric oxide fraction in adolescence. Eur Respir J 2016; 47: 510-519. 
39 Shaheen SO, Northstone K, Newson RB, et al. Dietary patterns in pregnancy and respiratory and atopic outcomes in childhood. Thorax 2009; 64: 411-417.

40 Rifas-Shiman SL, Rich-Edwards JW, Kleinman KP, et al. Dietary quality during pregnancy varies by maternal characteristics in Project Viva: a US cohort. J Am Diet Assoc 2009; 109: 1004-1011.

41 Willett WC, Lenart E. Reproducibility and validity of food-frequency questionnaires. In: Willett WC, Ed. Nutritional Epidemiology. 3rd ed. New York, Oxford University Press, 2012. pp. 96-141.

42 Howe LD, Tilling K, Galobardes B, et al. Loss to follow-up in cohort studies: bias in estimates of socioeconomic inequalities. Epidemiology 2013; 24: 1-9. 